\title{
A Ação Externa dos Governos Subnacionais no Brasill: Os Casos do Río Grande do Sul e de Porto Alegre. Um Estudo Comparativo de Dois Tipos de Atores Mistos*
}

\author{
Mónica Salomón** e Carmen Nunes***
}

\section{Introdução}

\begin{abstract}
A cada vez mais importante atividade externa de governos subnacionais (locais, provinciais, estaduais etc.) em todo o mundo tem des-
\end{abstract}

\footnotetext{
*Este artigo é fruto, por um lado, da pesquisa sobre a ação exterior da Prefeitura de Porto Alegre realizada por Mónica Salomón, entre maio e setembro de 2005, como bolsista do Ministério da Educação e Ciência da Espanha (programa de mobilidade de professores de universidades espanholas), no Instituto Latino-americano de Estudos Avançados (ILEA), Universidade Federal do Rio Grande do Sul (UFRGS); e, por outro, da dissertação de Mestrado de Carmen Nunes sobre a ação exterior do governo do Rio Grande do Sul (NUNES, 2005a) no Programa de Pós-graduação em Relações Internacionais da UFRGS. As autoras agradecem a colaboração das seguintes pessoas, que gentilmente aceitaram ser entrevistadas para as pesquisas que deram origem a este artigo: Denise de Oliveira Barreiro, Eduardo Mancuso, Florence Rosa, João Carlos Brum Torres, João Ferrer, Embaixador Jorge Carlos Ribeiro, Luciane Adami, Maire Loss, Sandra Schafer e Sara Brumer. Artigo recebido em dezembro de 2006 e aceito para publicação em janeiro de 2007.

**Mónica Salomón é professora do Instituto de Relações Internacionais da Pontifícia Universidade Católica do Rio de Janeiro (IRI/PUC-Rio).

***Carmem Nunes é professora da Faculdade Montserrat, RS.
} 
pertado um crescente interesse acadêmico. Cientistas políticos, sociólogos, geógrafos, economistas, urbanistas e estudiosos das Relações Internacionais - que, tradicionalmente, ocupam-se da análise das políticas externas de Estados-Nação - produziram, nos últimos anos, uma abundante literatura sobre os distintos aspectos e desafios que apresenta o fenômeno conhecido como "paradiplomacia" (DUCHACEK, 1990; SOLDATOS, 1993), "diplomacia das unidades constituintes" (KINCAID, 1990; 1991) ou "diplomacia federativa" (LAMPREIA, 1999), para citar somente alguns exemplos de suas múltiplas denominações.

O meio acadêmico brasileiro não é exceção. Existe, neste momento, um acervo bastante respeitável de artigos, livros, monografias, dissertações de Mestrado e teses de Doutorado dedicado à análise da atividade externa de entidades subnacionais em geral, bem como dos governos estaduais e municipais brasileiros que mais atuam nessa área (FARIAS, 2000; BARRETO, 2001; MATTOSO, 2001; BOGÉA, 2001; LESSA, 2002; VIGEVANI et al., 2004; NUNES, 2005a, 2005b, entre outros).

Este artigo pretende contribuir para o acervo existente. Nosso propósito é, ao mesmo tempo, descritivo e explicativo. Por um lado, interessa-nos documentar uma série de práticas interessantes em si mesmas, sobretudo por, dada a considerável volatilidade desse tipo de atuação, correrem o risco de cair rapidamente no esquecimento, deixando-se de aproveitar os ensinamentos que poderiam gerar, tanto para os analistas quanto para as próprias autoridades governamentais. Por outro lado, ao comparar as ações externas de entidades de dois níveis diferentes, pretendemos contribuir para a conceituação de dois tipos de atores internacionais: os governos locais e os governos regionais. Pelo que sabemos, pouco se fez até agora para caracterizar as especificidades de cada um desses atores de maneira sistemática. Tende-se a classificá-los na mesma categoria, fixando diferenças entre suas ações internacionais e as de governos centrais. Com este tra- 
balho, tentamos começar a preencher esse vazio conceitual e dar especial atenção aos traços específicos da atuação internacional de cada um desses atores, sem descuidar do que lhes é comum e do que os diferencia dos governos centrais.

Os dois objetos de estudo selecionados possuem atividade externa destacável e pioneira no contexto brasileiro. Tanto o Rio Grande do Sul quanto Porto Alegre se encontram, respectivamente, entre os primeiros estados e municípios do país que, deliberadamente, construíram uma estrutura e estratégias de ação externa. No caso de Porto Alegre, a permanência de um mesmo partido (o Partido dos Trabalhadores (PT)) no governo durante quatro gestões (1989-2004) permitiu pôr em prática uma ação externa estável e coerente. Já no estado, a alternância política levou a uma ação mais errática, porém significativa.

A análise comparativa de nossos objetos de estudo é facilitada pelo fato de Porto Alegre ser a capital do Rio Grande do Sul, já que numerosas variáveis suscetíveis de afetar seus comportamentos externos (localização geográfica, perfil sociopolítico da população, grau de desenvolvimento industrial etc.) são - cabe argumentar - de natureza similar. Em contrapartida, o fato de no período analisado só ter ocorrido coincidência entre as forças políticas no governo estadual e no municipal por quatro anos, de 1999 a 2002, é uma variável que não favorece nosso intento de comparação.

O núcleo deste artigo é a descrição e a comparação das dimensões institucional (estrutura paradiplomática) e substancial (agenda e instrumentos) da atuação externa do Rio Grande do Sul e de Porto Alegre. Antes de abordar tais dimensões, porém, é importante fazer algumas considerações sobre a caracterização dos governos subnacionais na disciplina de Relações Internacionais e sobre as possíveis especificidades dos dois tipos de governos de que nos ocupamos. 


\section{Os Governos Subnacionais nas Taxonomias de Atores Internacionais}

A distinção que se costuma fazer em Relações Internacionais entre atores estatais e atores não estatais não é muito útil em nosso intento de caracterizar os governos subnacionais como atores internacionais - já que, quando se fala em atores estatais, o que se faz, na verdade, é tratar da ação externa dos governos centrais, não da dos governos regionais ou locais. Por outro lado, de modo algum se pode dizer que os governos subnacionais sejam não estatais. Precisamente, uma das reivindicações tradicionais das associações e redes de autoridades locais tem sido que lhes seja permitido ocupar um espaço na tomada de decisões nos foros supranacionais e globais, com o argumento de que os governos locais e regionais também são Estado (SALOMÓN; SÁNCHEZ CANO, 2005). Da mesma maneira, tampouco o rótulo de atores transnacionais, empregado basicamente para descrever as atividades de Organizações Não Governamentais (ONG) e empresas multinacionais (MERLE, 1988; RISSE, 2002), adapta-se bem aos governos subnacionais, por mais que, em instâncias como as Nações Unidas, o tratamento que de fato recebem seja equiparável ao que se confere às ONGs (SALOMÓN, 2005, p. 81).

Por outro lado, a distinção já clássica de Keohane e Nye (1997) entre relações interestatais, transnacionais e transgovernamentais, ainda que mais afinada, também é insuficiente para nosso objetivo. Mesmo que os vínculos entre governos subnacionais possam entrar comodamente na categoria de relações transgovernamentais (as que vinculam os atores de diferentes estruturas de governos que estabelecem relações diretamente com representantes de estruturas similares em outros países com organismos internacionais e com atores não governamentais), nela também cabem vínculos de natureza muito diferente, como os contatos diretos, isto é, sem passar pelos filtros dos Ministérios de Relações Exteriores, entre ministros ou técnicos de 
uma mesma área. Assim, a categoria torna-se muito ampla e perde poder explicativo.

Mais útil para nosso intento de caracterização é a distinção de Soldatos (1990) entre a segmentação funcional a segmentação territorial da política externa, o que nos permite diferenciar conceitualmente as relações exteriores das diferentes burocracias que formam o governo central (por pior coordenadas que estejam com seus respectivos Ministérios de Relações Exteriores) das atividades internacionais dos governos subnacionais responsáveis por um território e uma população, que são os suscetíveis de embarcar em atividades paradiplomáticas. Precisamente por governar um território que contém uma população - atributos clássicos de estatalidade -, os governos subnacionais apresentam semelhanças importantes, tanto em sua estrutura interna como em seu relacionamento externo com os governos centrais. Também apresentam diferenças significativas: no que diz respeito a suas relações internacionais, está claro que governos subnacionais não podem ter uma política externa no sentido de alta políti$c a$, mas isso não lhes impede, em maior ou menor grau, segundo o sistema político de que fazem parte, de ter uma ação externa mais ou menos articulada, que, em certas ocasiões, entra no terreno do que normalmente se entende por política externa.

A partir dessas semelhanças e diferenças entre governos subnacionais e governos centrais, e o que acarretam em termos de relações internacionais, autores como Hocking (1997-2004) e Paquin (2004) consideram estes últimos como atores mistos, a meio caminho entre o que James Rosenau (1990, p. 36 et seq.) denominou "atores condicionados pela soberania" (sovereignty-bound) e "atores livres de soberania" (sovereignty-free). Cabe lembrar que a distinção estabelecida por Rosenau enfatiza o que as limitações e as responsabilidades da soberania podem representar para a ação exterior dos atores internacionais. Assim, os atores condicionados pela soberania (basicamente os governos centrais) estão obrigados por suas responsabilidades so- 
beranas a prestar atenção às múltiplas questões incluídas na agenda global e a distribuir seus recursos entre elas, enquanto os atores livres de soberania, com responsabilidades menos dispersas, têm liberdade para buscar objetivos mais limitados e concretos. Entre a variada gama de atores livres de soberania - empresas multinacionais, grupos étnicos, agências burocráticas e partidos políticos -, Rosenau incluía os governos subnacionais. Paquin e Hocking, no entanto, preferem situar os governos subnacionais em uma categoria mista, em que se combinam características dos atores condicionados pela soberania e dos livres. O caso de Québec, estudado por Paquin, ilustra bem essa ambígua condição de ator misto. Dado que o governo de Québec está incluído no sistema federal canadense, Paquin (2005, p. 6) considera que, de alguma maneira, Québec compartilha com o Canadá a soberania no seu território, o que lhe dá acesso a redes diplomáticas internacionais e a canais governamentais de decisão que o conectam com o governo federal canadense, permitindo-lhe ter também presença direta nas delegações canadenses no exterior. Por outro lado, Québec não é um protagonista oficial no cenário internacional e desfruta, assim, de prerrogativas típicas dos atores livres de soberania, tais como poder defender seus litígios em tribunais estrangeiros ou exercer atividades que parecem mais próprias de ONGs (por exemplo, participar do Fórum Social Mundial). Nessa mesma linha, Hocking (1997-2004, p. 87) assinala a maior liberdade de escolha com que contam os atores subnacionais - comparativamente aos governos centrais -, o que deriva do caráter discricionário das ações de política externa desses atores. Por não possuir competências em política externa, também não precisam assumir as responsabilidades inerentes a ela.

Portanto, pode-se considerar tanto os governos locais como os regionais como atores mistos, em parte livres de soberania, mas em parte condicionados pela soberania que compartilham com os demais níveis de governo do Estado a que pertencem. Como esses dois tipos de atores conjugam as características próprias dos atores condicionados 
pela soberania e as dos livres? Há diferenças significativas entre a ação encaminhada nesse sentido pelos governos locais e pelos regionais? Acreditamos que a análise comparativa dos casos de Porto Alegre e do Rio Grande do Sul pode nos ajudar a responder a essas perguntas.

\section{O Desenvolvimento de Estruturas Institucionais Paradiplomáticas}

Tal como se costuma assinalar, a criação de uma estrutura institucional específica de relações internacionais no aparato administrativo de um governo subnacional denota não o começo de uma atuação internacional, mas sua intensificação e a vontade de agir mais organizadamente do que até então. De modo semelhante ao que ocorre em nível central, nessa era de fluidez de contatos o corrente é que os distintos órgãos dos governos subnacionais (secretarias, departamentos etc.) mantenham contatos com órgãos equivalentes ou com outros interlocutores no exterior; mesmo assim - e cada vez mais -, a existência de uma instância não monopolizadora, porém coordenadora da ação exterior do governo, é uma das principais ferramentas paradiplomáticas com que se conta. Todos os governos centrais e regionais com atividade internacional significativa dispõem de uma estrutura institucional que coordena ou trata de coordenar as relações exteriores. Para avaliar a ação exterior dos atores que consideramos, portanto, é fundamental levar em conta o processo de construção e evolução das respectivas estruturas institucionais paradiplomáticas.

\section{A Estrutura Paradiplomática do Rio Grande do Sul}

Há dois momentos bem diferenciados na institucionalização da paradiplomacia no Rio Grande do Sul. O primeiro, que vai de 1987 a 
1994, coincide com o intento de coordenar a ação exterior do estado por meio da Secretaria Especial para os Assuntos Internacionais (SEAI). No segundo momento, de 1995 em diante, a SEAI foi substituída pela Secretaria do Desenvolvimento e dos Assuntos Internacionais (Sedai), que, mesmo não sendo um órgão formal de coordenação, opera como instância paradiplomática do governo e como coordenadora de facto de, ao menos, uma parte de suas atuações internacionais.

\section{Primeira fase: a SEAI e a tentativa de coordenação}

Quando a SEAI foi estabelecida, no governo de Pedro Simon (Partido do Movimento Democrático Brasileiro (PMDB), 1987-1990), somente o governo do Rio de Janeiro havia desenvolvido uma experiência similar no Brasil. ${ }^{1}$ As funções do novo órgão, conforme o decreto 32.515, de 15/3/1987, eram assessorar o governador nas relações com outros países, principalmente os da Bacia do Prata, e com organismos internacionais; supervisionar e orientar os órgãos de governo em ações externas; captar recursos e investimentos; e apoiar o setor privado em projetos com participação externa.

O quadro da SEAI foi formado aos poucos, com técnicos cedidos por outros órgãos, na maioria advogados, administradores, economistas e sociólogos, além de pessoal administrativo. Ao final do governo Simon, havia cerca de trinta servidores, média que foi mantida no governo seguinte, de Alceu Collares (Partido Democrático Trabalhista (PDT), 1991-1994).

A integração regional, principalmente o acompanhamento do Programa de Integração e Cooperação Econômica (PICE) entre Brasil e Argentina, era o assunto de maior relevância para a SEAI em seus anos iniciais. Com o aumento do número de servidores, passou-se a tratar também de cooperação internacional, de atração de investi- 
mentos e de apoio às exportações. Esses temas se refletiam na estrutura do órgão que, ao final do governo Simon, compunha-se das Coordenadorias de Cooperação Internacional, de Apoio a Investimentos Privados e de Integração com a América Latina, esta subdividida na Divisão de Integração e na de Cooperação Cultural. A organização em coordenadorias e divisões seguia o modelo estrutural do Itamaraty.

No governo de Collares, mesmo com sua extinção tendo sido cogitada, a SEAI foi fortalecida. Sua estrutura demonstra isso: nos três primeiros anos, mantiveram-se as três coordenadorias e as divisões passaram de duas para nove, refletindo o aumento e uma maior especialização das atividades. ${ }^{2}$ Em 1994, a SEAI passou por modificações que equipararam sua estrutura a de outras secretarias.

O fortalecimento percebido na estrutura, porém, não foi suficiente para manter a SEAI em funcionamento quando houve nova troca de governo. O governador Antônio Britto (PMDB, 1995-1998) extinguiu-a em 1995 e criou a atual Sedai, que encampou temas tratados pela SEAI e pela Secretaria de Indústria e Comércio (SIC).

Há vários fatores que explicam por que isso ocorreu. Primeiramente, mesmo com a SEAI tendo sido criada para "supervisionar e orientar" as ações externas do estado, esse objetivo não foi satisfatoriamente atingido durante os oito anos de sua existência. Houve conflitos com outros órgãos e ações paralelas ao longo de todo o período. Por exemplo, até 1994 era a área da Justiça que recebia os visitantes diplomáti$\cos$, freqüentemente deixando de informar a SEAI acerca das visitas. Houve seguidas controvérsias na esfera da promoção comercial e da atração de investimentos, temas desenvolvidos há mais tempo pela área de indústria e comércio e que se tornaram foco também das ações da SEAI no governo Collares. Além disso, ao mesmo tempo que surgia a SEAI, era criado, na Secretaria de Coordenação e Planejamento (SCP), um setor para negociar recursos financeiros e técni- 
cos com agências internacionais, em uma clara superposição de funções. Ou seja, a criação da SEAI não foi acompanhada por uma reestruturação que centralizasse nesta Secretaria a coordenação das funções de caráter internacional desenvolvidas pela administração estadual.

Em segundo lugar, a maneira de o Itamaraty relacionar-se com a SEAI e com outras instâncias da administração estadual não contribuiu para consolidar a Secretaria como o órgão responsável pelos assuntos internacionais do estado. Após a criação da Secretaria, o Ministério das Relações Exteriores (MRE) continuou tratando diretamente com os demais órgãos do governo estadual (SEITENFUS, 1994) e, mesmo que com o passar do tempo as relações entre o Ministério e a Secretaria tenham se intensificado, os contatos diretos com outros órgãos nunca foram abandonados.

Em terceiro lugar, as frequientes trocas de titulares - nove secretários em oito anos - e o fato de que muitos deles não tinham preparação em temas internacionais ${ }^{3}$ reduziram as possibilidades de atuação da SEAI como órgão de coordenação efetivo.

\section{Segunda fase: a Sedai - coordenação de facto e redução do escopo}

A fusão das áreas de indústria e comércio e de assuntos internacionais, dando origem à Sedai, em 1995, tinha por principal objetivo "assegurar a integração do Rio Grande do Sul no mercado internacional, especialmente no que diz respeito ao Mercosul" (SCP, 1996, p. 19), sobretudo mediante a promoção da indústria, do comércio e da atração de investimentos. Formalmente, então, a nova Secretaria não era uma instância de coordenação da atividade exterior do governo estadual, como fora a SEAI. 
Entretanto, logo a Sedai preencheu o vazio deixado por sua antecessora - cujos funcionários herdou - cumprindo, de facto, funções claramente paradiplomáticas, se bem que com um alcance mais reduzido do que a SEAI. Isso ocorreu porque as demais secretarias de governo continuaram recorrendo à Sedai em temas pontuais, basicamente buscando orientação ao enfrentar problemas em suas ações externas. Em parte, isso se explica porque os demais órgãos não possuem servidores com conhecimento ou experiência em assuntos internacionais. A Sedai também permaneceu como a instância de referência para os temas mais políticos, tanto é que as relações com o Itamaraty, com governos subnacionais estrangeiros e com diplomatas mantiveram-se em sua alçada. Houve mesmo uma maior aproximação com o MRE com a abertura, em 1995, de um escritório de representação do Ministério, o Escritório de Representação no Rio Grande do Sul (Eresul), em salas cedidas pela Sedai - o que não implicou o fim dos contatos diretos com as demais secretarias.

Quanto a sua estrutura, inicialmente, a Sedai contava com dois departamentos, o de Integração com a América Latina e o de Cooperação e Negócios Internacionais. Em 1996, eles foram unificados no Departamento de Assuntos Internacionais e de Integração Latino-Americana (DIN), composto por cinco divisões ${ }^{4}$ com raio de atuação mais restrito do que na SEAI. Não houve continuidade, por exemplo, de programas de cooperação com países em desenvolvimento ou de estudos sobre os impactos da integração regional para o estado. Buscou-se dotar as ações do novo Departamento de um caráter mais comercial, o que também ocorreu nos governos seguintes.

O governo de Olívio Dutra (PT, 1999-2002) manteve a unificação das áreas do desenvolvimento econômico e das relações internacionais na Sedai, mas a estrutura do DIN foi modificada novamente, sendo criadas as áreas de Negócios Internacionais, mais voltadas a assuntos econômicos, e a de Assuntos Internacionais, com mais ênfase em aspectos políticos. ${ }^{5} \mathrm{~A}$ integração regional ganhou novamen- 
te uma estrutura exclusiva de coordenação, o Gabinete Extraordinário para Assuntos do Mercosul, porém a experiência durou menos de um ano. Sua existência esteve mais vinculada à satisfação de interesses de partidos que apoiaram a candidatura de Olívio do que a uma política estratégica de governo voltada aos assuntos do Mercosul.

O governo seguinte, de Germano Rigotto (PMDB, 2003-2006), manteve a divisão do DIN entre as áreas "política" e "econômica". Interessante ressaltar que o principal interesse desse governo na esfera externa, a atração de investimentos, não é função do DIN, mas sim do secretário da Sedai e do próprio governador, como já ocorrera durante o governo de Antônio Britto, também do PMDB à época.

Essas contínuas mudanças na estrutura da área internacional do Rio Grande do Sul, ao longo de vinte anos, permitem afirmar que os governos não encontraram uma fórmula que respondesse adequadamente às necessidades da atuação externa do estado. Essa indefinição organizacional também dá conta do baixo comprometimento institucional com os assuntos internacionais, ficando a continuidade de ações no plano externo na dependência do interesse de governadores ou de secretários da área.

\section{A Estrutura Paradiplomática de Porto Alegre}

Como o Rio Grande do Sul entre os estados, Porto Alegre foi um município pioneiro no Brasil no estabelecimento de uma instância de coordenação das relações internacionais dos órgãos do governo local. Sobre as bases do Gabinete Extraordinário para a Captação de Recursos, de 1993, o prefeito Tarso Genro (PT, 1993-1996) estabeleceu, em 1994, a Secretaria Extraordinária de Captação de Recursos (Secar). Ainda que somente em 1996 a Secar tenha passado a chamar-se Secretaria Extraordinária de Captação de Recursos e Coope- 
ração Internacional, desde 1994 suas funções incluíam a coordenação da cada vez mais abundante agenda de relações internacionais da Prefeitura em sua totalidade.

É interessante o fato de que a lógica de criação do embrião da Secar, o Gabinete Extraordinário, não distinguia entre a dimensão nacional e a internacional: o objetivo do gabinete era captar recursos de agências tanto nacionais quanto internacionais para financiar projetos de infra-estrutura ou de fins sociais. Mesmo assim, as principais fontes dos recursos captados foram agências internacionais como Banco Mundial, Banco Interamericano de Desenvolvimento (BID) e Fondo Financiero para el Desarrollo de la Cuenca del Plata (Fonplata), que, justamente naquele momento, começavam a negociar diretamente com alguns governos subnacionais. A constituição do Gabinete foi fundamental para reivindicar, com êxito, perante as agências internacionais, a possibilidade de negociar acordos diretamente, com o aval do governo central. Porto Alegre, juntamente com São Paulo, foi uma das primeiras prefeituras do país a conseguir isso.

Um segundo aspecto relativo à criação do Gabinete/Secar é que se tratou de uma iniciativa "importada" do governo estadual. Efetivamente, o artífice do Gabinete, João Carlos Brum Torres, pusera em marcha, durante o governo de Simon no Rio Grande do Sul, uma estrutura bem-sucedida de captação de recursos destinados a investimentos em periferias urbanas, conseguindo dar início à primeira negociação internacional direta do estado gaúcho com uma agência internacional, o Banco Mundial. É de se destacar que Brum Torres não pertencia ao PT, sendo uma figura de relevo no PMDB. Ou seja, a origem da estrutura de coordenação das relações internacionais da Prefeitura de Porto Alegre foi politicamente neutra.

Quando Brum Torres deixou o Gabinete para se dedicar à campanha eleitoral estadual, em meados de 1994, o balanço dos onze meses de sua gestão era muito bom. Incluía a abertura de negociações com o 
Fonplata para melhorar o sistema de Pronto-socorro e o planejamento da agência de microcrédito Portosol. Após sua saída, o prefeito Tarso Genro, apoiado pelo primeiro secretário da Secar, o sociólogo José Utzig, transformou o Gabinete de Captação de Recursos em uma secretaria permanente, que passou a abranger a coordenação - ao menos em teoria - de todas as atividades internacionais da Prefeitura.

Na nova estrutura, as atividades de captação de recursos ocupavam um lugar proeminente, dedicando-se a elas uma das duas coordenadorias da Secretaria e, aproximadamente, a metade dos funcionários. A outra seção, a Cordenadoria de Cooperação Internacional, ocupava-se de supervisionar as atividades internacionais da Prefeitura e das funções de comunicação e de relações públicas, dentro das quais se incluíam a preparação das viagens do prefeito e dos secretários, a recepção de delegações estrangeiras, a celebração de acordos de cooperação com outras prefeituras ou agências, a participação em organizações e redes etc. Cada uma das seções contava com três ou quatro servidores, em geral advogados, economistas e sociólogos, além do coordenador e pessoal de apoio administrativo.

A opção de manter juntas, ainda que com certa autonomia, a estrutura "política" e a estrutura "econômica" do aparato paradiplomático funcionou bem. Dado que a atividade da estrutura econômica estava restrita à captação de recursos de agências públicas, os conflitos de interesses que às vezes ocorrem entre os lados político e econômico dos aparatos diplomáticos ou paradiplomáticos não tiveram lugar. Ademais, o setor de captação de recursos beneficiava-se da presença na Secar do setor de cooperação, por meio do qual seus servidores tomavam conhecimento de novas fontes potenciais de financiamento internacional.

A estrutura da Secar permaneceu igual até o início do ano 2001, isto é, até o início da quarta administração do PT, novamente com Tarso Genro como prefeito. A permanência do mesmo partido no poder foi uma condição necessária para a estabilidade institucional, ainda que, 
evidentemente, a manutenção da estrutura se devia, antes de tudo, à satisfação com seu funcionamento. Como veremos na próxima seção, ambos os setores da Secar logo tiveram êxitos e viram suas atividades consideravelmente incrementadas em poucos anos.

Na verdade, a mudança de 2001 deveu-se precisamente ao êxito da Secar e, mais especificamente, à estratégia de internacionalização e de image building de Porto Alegre desenvolvida pela coordenadoria de cooperação internacional. Em 2001, Porto Alegre tinha uma atividade internacional importante, um perfil bem definido e a grande responsabilidade de acolher o primeiro Fórum Social Mundial (FSM). Cabendo ao prefeito desempenhar o papel de principal representante da cidade perante instâncias e interlocutores internacionais, é natural - em termos de eficácia e, também, de rentabilidade política - a decisão de Tarso Genro de separar os dois setores da Secar e levar a parte de cooperação internacional para seu próprio gabinete. Não parece casual que essa inovação nas estruturas, acompanhada, como veremos, de iniciativas substanciais de intervenção internacional, tenha ocorrido na administração Genro, o artífice da Secar e, sem dúvida, o prefeito mais ativo internacionalmente dos quatro que ocuparam o cargo com o PT.

Ainda que a separação entre a esfera propriamente paradiplomática e a de captação de recursos tenha causado algumas disfunções (a área de captação de recursos deixou de beneficiar-se das informações sobre projetos potenciais que lhe repassava o setor de cooperação), as funções dos dois componentes originais da Secar seguiram sendo fundamentalmente as mesmas. Ademais, a continuidade no trabalho da área política ficou assegurada por ter sido mantida a mesma equipe, incluindo seu responsável, que, de coordenador de cooperação internacional na Secar, passou a ser assessor de relações internacionais no gabinete do prefeito.

Com a saída do PT da Prefeitura e sua substituição por uma coalizão de centro-direita, em janeiro de 2005 , voltou-se a reunir praticamente todas as atividades internacionais em um único órgão, com exce- 
ção do Programa Urb-Al, dependendo as ações em cada uma das redes de que Porto Alegre participa da secretaria que se ocupa de cada temática específica. Esse órgão passou a denominar-se Gabinete de Captação de Recursos e Investimentos (Captare). O Captare manteve, além do mais, o modelo dual da Secar, com um setor encarregado da cooperação internacional e outro da captação de recursos, com uma nova ênfase na captação de investimentos privados. Fundamentalmente, então, o modelo organizacional simples da Secar manteve-se mesmo com a mudança política na administração, o que constitui uma demonstração clara de satisfação com seu funcionamento.

\section{As Estruturas Institucionais Paradiplomáticas do Rio Grande do Sul e de Porto Alegre: Elementos de Comparação}

Concluímos esta seção comparando os aspectos das estruturas institucionais paradiplomáticas do Rio Grande do Sul e de Porto Alegre, que, a nosso ver, são as mais relevantes, e tentamos determinar em que medida Rio Grande do Sul e Porto Alegre se comportam, nesses aspectos, como atores "típicos" de suas respectivas categorias - governo regional e governo local - e até que ponto se pode supor que suas características estejam determinadas por outros fatores.

O primeiro aspecto que consideramos é o grau de inovação institucional que levou, em cada caso, à criação de uma estrutura dedicada às relações internacionais. Como vimos, tanto o Rio Grande do Sul quanto Porto Alegre foram pioneiros na criação de estruturas paradiplomáticas, mas o estabelecimento da SEAI no estado ocorreu em 1987, antecedendo em sete anos a Secar, criada em 1994. Além disso, como vimos, o gérmen da Secar, o Gabinete Extraordinário de Captação de Recursos, foi uma iniciativa importada do governo estadual, mesmo que não sendo da SEAI. É bastante plausível, porém, 
que a existência da SEAI tenha sido um estímulo importante para a criação da Secar.

Neste sentido, o pioneirismo do Rio Grande do Sul e sua influência na criação de uma estrutura com características similares em Porto Alegre expressa uma tendência típica: em todo o mundo a institucionalização da paradiplomacia foi uma iniciativa que partiu dos governos regionais e, uma vez consolidada, foi assumida também pelos governos municipais. Em outras palavras, geralmente as cidades seguem a trilha percorrida pelas regiões. Isso é assim por duas razões principais. A primeira relaciona-se com a maior capacidade dos governos regionais, normalmente com mais recursos materiais e de poder que os municípios, para reivindicar com êxito junto ao governo central repasses formais ou informais de competências. É preciso levar em conta que, em geral, estabelecer uma estrutura institucional dedicada à ação exterior e, sobretudo, colocar em prática uma estratégia exterior definida supõem um enfrentamento com o governo central ou, ao menos, uma ruptura de esquemas. Nesse sentido, os governos regionais estavam mais bem preparados que os locais para assumir um papel de vanguarda na defesa do regionalismo. A segunda razão relaciona-se com as motivações. Os governos regionais e os municipais compartilham a busca de benefícios econômicos e os da cooperação internacional, mas as motivações nacionalistas, quando existem, são exclusivas de governos regionais. Em muitos casos, uma atividade internacional intensa, entendida como "protodiplomacia”, é um meio de definir a própria identidade e o complemento de reivindicações autonomistas. Ainda que, no Brasil, esse tipo de motivação não conte, certamente a criação de estruturas paradiplomáticas em outras regiões do mundo, cujos governos eram impulsionados por razões nacionalistas, inspirou os projetos dos primeiros governos estaduais que o puseram em prática.

O segundo aspecto que, em nosso entender, merece ser comparado é o da estrutura dos respectivos aparatos paradiplomáticos. O primei- 
ro, que salta aos olhos nesse sentido, é a maior dimensão e complexidade da estrutura estadual, que conta com mais funcionários e maior especialização dos componentes. Também aqui é bastante evidente a conexão entre as dimensões e complexidades respectivas de estados e cidades e as dimensões dos aparatos dos governos estaduais em geral e das prefeituras. Mas se prestarmos atenção à lógica da organização de ambos os aparatos, comprovamos que, apesar das variações que ocorreram ao longo do tempo, sobretudo no caso do Rio Grande do Sul, o modelo que acabou prevalecendo nos dois casos foi o da diferenciação, ainda que em estreita associação, de duas dimensões bem definidas: a econômica, dominada pela captação de recursos e de investimentos e por ações de promoção comercial, e a política e de cooperação. No Rio Grande do Sul, esse modelo foi iniciado por Olívio Dutra, em 1999, e continua vigente até a atualidade. Esse também foi o modelo prevalente em Porto Alegre, exceto no interlúdio da segunda administração de Tarso Genro, continuada por João Verle. Nossa interpretação, bastante tentativa, é que esse esquema, que obviamente não corresponde a uma diferenciação entre estruturas próprias de governos regionais e governos municipais, é mais freqüente nas paradiplomacias do Terceiro Mundo que nas do mundo desenvolvido. Isso seria assim porque, na ação exterior dos governos de países desenvolvidos, qualquer que seja o nível, são mais evidentes as contradições entre os objetivos vinculados à cooperação (que costuma ser assimétrica e favorecer o interlocutor não desenvolvido) e os econômicos (que costumam incluir o apoio às empresas nacionais que atuam no mundo em desenvolvimento). De todo modo, é evidente que a diversidade das estruturas paradiplomáticas é enorme e resulta praticamente impossível estabelecer uma tipologia.

Uma terceira questão que queremos comparar é a da eficácia de ambos os aparatos paradiplomáticos nas tarefas de coordenação da atividade exterior. Nossos estudos refletiram um grau maior de satisfação dos responsáveis pela política exterior no caso de Porto Alegre 
do que no do Rio Grande do Sul. A contraposição entre a grande estabilidade política de Porto Alegre e a pouca estabilidade vivida no Rio Grande do Sul é um elemento importante da explicação e obscurece outros fatores possíveis inerentes ao nível de governo. De qualquer modo, queremos apontar que o reduzido aparato de Porto Alegre é mais simples de gerir que o complexo aparato paradiplomático do Rio Grande do Sul, que deve fazer frente a uma agenda não muito diferente, no que diz respeito à baixa política, da de um governo central. Nesse sentido, a combinação dessa agenda complexa com práticas que não são, como as do Estado central, de government (obrigatórias, bem estabelecidas e com um marco jurídico claro), e sim de governance (livremente decididas e cambiáveis), opera em detrimento da eficácia da gestão. Essa consideração se aplica não somente ao aparato paradiplomático do Rio Grande do Sul como ao de qualquer governo regional.

O quarto e último aspecto a que queremos dedicar atenção é o da estrutura paradiplomática como canal de comunicação entre o governo não central e o central. Uma vez mais aparecem algumas diferenças que muito obviamente apontam para as características das duas categorias diferentes de atores. $\mathrm{O}$ governo central brasileiro relaciona-se com todos os governos regionais, e o Itamaraty estabeleceu escritórios de representação em alguns estados. Isso não quer dizer que o relacionamento seja perfeito. Como vimos, o fato de o Eresul estar situado nas dependências da Sedai não evitou que, em muitos casos, o governo central usasse outros canais de comunicação com as distintas secretarias do governo regional e "ignorasse" a Sedai. Ademais, diferentemente do que ocorre em países como Canadá, Alemanha ou Austrália, no Brasil não há estruturas institucionalizadas de diálogo com os governos subnacionais para tratar de temas exteriores que afetem esses governos. ${ }^{7}$

Mas a relação do Itamaraty é menos direta com os governos municipais, provavelmente por causa do grande número de municípios no 
país e, também, por sua menor envergadura como promotores de desenvolvimento econômico. O relacionamento do MRE com essa esfera de governo se dá mais por meio de associações de municípios do que diretamente. Um outro motivo para esse menor relacionamento direto está nas agendas de relações internacionais desenvolvidas pelos municípios: são mais específicas, pontuais, voltadas aos temas locais, enquanto as agendas estaduais costumam assemelhar-se mais à do governo central. Isso leva a um maior interesse do governo central em conhecer e, se necessário, controlar o que os governos regionais estão desenvolvendo na esfera externa. Também nessa dimensão os governos do Rio Grande do Sul e de Porto Alegre estariam seguindo pautas de comportamento habituais em suas categorias.

\section{As Agendas Externas: Focos de Interesse e Instrumentos}

Passamos agora a considerar a ação exterior em si mesma dos atores analisados. Excluída a alta política, prerrogativa exclusiva do governo central, a agenda exterior dos governos subnacionais articula-se em torno de duas grandes dimensões: a promoção econômica e a cooperação política e técnica. Uma possível terceira dimensão, a da integração regional, é, na realidade, transversal às outras duas e conjuga-se com elas. Corresponde a cada ator determinar como combinar essas diferentes dimensões e que conteúdo lhes dar. Ao considerar as agendas internacionais de Porto Alegre e do Rio Grande do Sul, interessa-nos averiguar em que medida a configuração da agenda obedece à condição de governo local ou regional e em que medida a outros fatores. Da mesma maneira, interessa-nos averiguar até que ponto os instrumentos empregados para pôr em prática a agenda internacional são instrumentos mais "típicos" dos governos locais ou dos regionais. 


\section{A Agenda Externa do Rio Grande do Sul}

Ao analisarmos as principais ações do Rio Grande do Sul no plano internacional, percebemos a recorrência de três temas principais, com importantes desdobramentos em sua agenda: a integração regional, a inserção na economia mundial e a cooperação internacional. Apesar dessa constância, não há elementos que indiquem a existência de uma estratégia contínua, refletida e articulada para agir na esfera externa.

\section{A integração regional}

A experiência do Rio Grande do Sul com a integração é marcada pela falta de continuidade de suas ações. Ao analisar os governos de São Paulo, Barreto (2001) cita estudo de Pastor e Wise (1994) sobre a criação do Acordo de Livre Comércio da América do Norte (em inglês, North American Free Trade Agreement (NAFTA)), em que se demonstra que os atores se mobilizam quando atingidos de forma negativa, mais ainda se esses efeitos se concentram em segmentos específicos; já as conseqüências positivas levam a uma menor mobilização, mesmo nula, em favor do processo de integração. Para a autora, isso pode explicar o baixo envolvimento de governos paulistas com os temas da integração, já que esse processo proporcionaria mais benefícios do que prejuízos para o estado. No caso do Rio Grande do Sul, parece ser possível utilizar o mesmo raciocínio. No início das negociações entre Brasil e Argentina, quando ainda havia muitos temores sobre os efeitos da integração para o território regional, foram criados diversos instrumentos para debater os interesses do estado e para influenciar as instâncias negociadoras. Quando os efeitos positivos começaram a ser sentidos, esses instrumentos foram perdendo força, a ponto de serem extintos. Mesmo os temas comerciais perderam seu poder de mobilização, a não ser em questões pontuais, como nas recentes tratativas acerca do arroz no Mercosul. 
O ponto de maior mobilização no governo estadual com relação à integração regional deu-se com a assinatura dos 24 protocolos de cooperação entre Brasil e Argentina, na segunda metade dos anos 1980. Isso gerou sentimentos ambíguos no Rio Grande do Sul. Por um lado, temiam-se prejuízos em função das semelhanças entre sua economia e a do Prata e da possibilidade de preponderância de interesses da indústria paulista nas negociações. Ao mesmo tempo, viam-se nas tratativas estímulos para o aumento de fluxos comerciais, o desenvolvimento fronteiriço e a cooperação entre povos com similaridades culturais e históricas. Os principais motivos para a criação da SEAI, em 1987, foram, então, a definição dos interesses do Rio Grande do Sul e sua defesa junto ao governo federal e às instâncias negociadoras.

Para tal, uma das estratégias iniciais da Secretaria foi apoiar a realização de diversos seminários e estudos sobre os impactos da integração para o estado e sobre crescimento integrado nas fronteiras com a Argentina e o Uruguai. Após a assinatura do Tratado de Assunção, em 1991, constituindo o Mercosul, buscou-se uma maior participação institucionalizada da sociedade na definição de interesses do Rio Grande do Sul, o que se deu com a criação da Comissão Estadual para o Desenvolvimento Integrado da Fronteira (CEDIF) e do Fórum Permanente do Mercosul. Também havia a preocupação em coordenar as ações do governo estadual sobre o Mercosul e, para tal, foi criada a Coordenadoria do Mercosul, dirigida pela SEAI e formada por grupos de técnicos de diferentes órgãos que reproduziam os subgrupos de trabalho do Grupo Mercado Comum. Sugestões oriundas desses espaços de discussão eram encaminhadas às instâncias negociadoras do acordo. Com a transformação da SEAI em Sedai, nenhuma dessas iniciativas teve continuidade.

Uma forma de defesa de interesses regionais - que merece destaque por sua inovação no contexto brasileiro - foi o incentivo da SEAI à aproximação de governos subnacionais argentinos e brasileiros, ${ }^{8} \mathrm{o}$ 
que resultou na assinatura, em 1988, do "Protocolo número 23: Regional Fronteiriço" entre os dois países. Esse ato criou um grupo de trabalho com governos subnacionais e centrais para tratar do desenvolvimento fronteiriço e instituiu os Comitês de Fronteira, órgãos compostos por autoridades locais e presididos por representantes consulares para debater temas socioeconômicos e problemas operativos de fronteira sem precisar recorrer aos governos centrais. Após alguns anos de pouca atividade do grupo de trabalho, criou-se, em 1995, o Fórum de Governadores do Conselho de Desenvolvimento e Integração Sul e da Comissão Regional de Comércio Exterior do Nordeste e Litoral da Argentina (Codesul-Crecenea Litoral) e onze Grupos de Integração Temática (GITs), compostos por representantes dos governos subnacionais. ${ }^{9}$ Houve diversas reuniões técnicas e nove encontros de governadores entre 1995 e 2000, ano este em que as ações perderam força por causa da crise econômica argentina.

No governo de Olívio Dutra, houve a tentativa de novamente coordenar as ações do governo na esfera da integração regional. Como mencionado anteriormente, foi criado o Gabinete Extraordinário para Assuntos do Mercosul, mas a experiência durou menos de um ano. Esse governo também se esforçou para criar o Fórum de Governadores do Mercosul, que reuniu em Porto Alegre, em 2001, governadores e representantes de diversos governos regionais dos países-membros e associados do Mercosul. Objetivava-se manter uma regularidade de reuniões e definir temas de consenso para defender junto aos governos nacionais. A iniciativa, porém, não foi além do primeiro encontro.

Atualmente, o tratamento de temas do Mercosul tem pouca relevância na área internacional. A Sedai tem-se limitado a tomar conhecimento das negociações entre os governos centrais e a atender a demandas surgidas principalmente de municípios fronteiriços e do Itamaraty. Um exemplo disso ocorre na Nova Agenda para a Cooperação e o Desenvolvimento Fronteiriço, iniciada pelos governos do 
Brasil e do Uruguai em 2002 e que reúne representantes de órgãos estaduais e municipais das áreas de saúde, segurança, educação, meio ambiente e saneamento: a Sedai toma conhecimento dos temas tratados, mas não interfere no andamento da iniciativa e não busca coordenar o posicionamento do Estado nas discussões.

\section{A promoção econômica}

Desde a criação da SEAI, o desenvolvimento da economia regional foi uma constante nas ações e projetos da área internacional. Nos primeiros anos, esses temas ainda eram muito incipientes, mas houve esforços para promover o comércio no Cone Sul e a criação de empresas binacionais. No início dos anos 1990, durante o governo Collares, a Secretaria lançou a Bolsa de Negócios, rede que propiciava intercâmbio entre empresas do Mercosul. A SEAI também passou a divulgar oportunidades de negócios internacionais colhidas em redes do MRE e da Comissão das Comunidades Européias (CCE). Houve, igualmente, um esforço conjunto entre SEAI, entidades empresariais, bancos, universidades e a Prefeitura da capital para a instalação de um Trade Point em Porto Alegre, o segundo no país. Promovidos pela Conferência das Nações Unidas sobre Comércio e Desenvolvimento (em inglês, United Nations Conference on Trade and Development (UNCTAD)), os Trade Points objetivam facilitar o acesso ao comércio internacional para pequenas e médias empresas, agrupando fisicamente representantes de alfândegas, bancos, operadoras de transporte, seguros e câmaras de comércio. Além disso, a Secretaria organizou missões empresariais a feiras de negócios no exterior e, pela primeira vez, as missões lideradas pelo governador tiveram também foco comercial, pois até então estavam voltadas à cooperação técnica e financeira.

Durante o governo Britto, a agenda da área internacional passou definitivamente a destacar os temas de promoção econômica, principalmente a atração de investimentos externos e a promoção das exporta- 
ções. Várias empresas transnacionais anunciaram investimentos no estado no período. Além dos incentivos fiscais do governo gaúcho, muitas delas afirmaram que pesou em sua decisão a localização do estado no Mercosul (MACADAR, 1999). Negociavam com as multinacionais os secretários, seus assessores diretos e o próprio governador. Aos técnicos da área internacional, cabiam ações de promoção das exportações, como a realização de seminários regionais para a sensibilização de empresas para o comércio internacional e a organização de missões governamentais e empresariais ao exterior.

No governo de Olívio Dutra, a promoção econômica manteve-se preponderante - não mais a atração de investimentos produtivos estrangeiros, mas a inserção das empresas gaúchas na economia globalizada. Suas principais estratégias envolveram o apoio financeiro e logístico à participação de empresas em feiras internacionais, cursos de capacitação em comércio exterior para empresários, o estímulo à formação de consórcios de exportação, a criação de escritórios do Trade Point no interior do estado, a realização de rodadas de negócios entre as representações comerciais de diversos países com empresários gaúchos e missões governamentais e empresariais ao exterior. É de se destacar que Olívio Dutra foi o primeiro governador brasileiro a liderar uma missão governamental e empresarial à China. Seguindo uma estratégia adotada por alguns governos subnacionais estrangeiros, a Sedai buscou abrir escritórios de representação do Rio Grande do Sul em Miami, nos Estados Unidos, e em Hubei, na China, declarada província-irmã do estado em 2001. Foram feitas tratativas com possíveis parceiros, mas os projetos não foram concluídos e o governo seguinte não deu andamento às iniciativas. Tentou-se, igualmente, instalar um escritório da Organização de Desenvolvimento Industrial das Nações Unidas (em inglês, United Nations Industrial Development Organization (UNIDO)) em Porto Alegre, mas as negociações tampouco prosseguiram no governo seguinte.

A ação da Sedai que gerou mais polêmica na gestão Dutra foi a renegociação de contratos com empresas multinacionais firmados pelo 
governo anterior. Houve novas tratativas com a General Motors, a Dell Computers e a Ford. Com as duas primeiras, chegou-se a um entendimento, mas a Ford encerrou as negociações e instalou-se na Bahia. Essa renegociação foi um dos pontos mais discutidos pelos partidos opositores na propaganda eleitoral em 2002, quando o governador buscou a reeleição e perdeu.

A partir de 2003, com o governo de Germano Rigotto (PMDB), houve novo redirecionamento na agenda internacional do estado, com a atração de investimentos externos produtivos ocupando novamente o lugar de destaque. Como ocorrera no governo Britto, a área internacional não se envolveu nessas ações, ficando as negociações a cargo do secretário da pasta e do governador. Premido por uma situação financeira crítica, esse governo reduziu o âmbito das ações da área internacional da Sedai, a qual está novamente voltada a promover as exportações. Foram mantidos o apoio à participação de empresas em feiras de perfil internacional e as rodadas de negócios com representantes diplomáticos. Inovações foram a criação da Sala do Exportador, que centraliza em um único lugar serviços de orientação sobre o comércio exterior para potenciais exportadores, e o lançamento do Fórum Permanente das Exportações, que reúne as diferentes organizações envolvidas no processo de exportar para debater estratégias de estímulo ao comércio exterior.

\section{A cooperação técnica internacional}

Nos governos de Simon e de Collares, as ações de cooperação internacional pareciam ter um futuro promissor, principalmente pelo relacionamento com a Agência Brasileira de Cooperação (ABC), mas, posteriormente, perderam importância e, sobretudo, articulação.

Durante o período em que a SEAI coordenou os assuntos internacionais, foram feitos levantamentos de técnicos aptos a prestarem cooperação técnica no exterior e cadastramento de servidores em órgãos 
da administração estadual que a informariam sobre as necessidades técnicas e financeiras de suas áreas e divulgariam as oportunidades recebidas. Esse tipo de coordenação permitiu a realização de diversos projetos com a $\mathrm{ABC}$, inclusive a oferta de cooperação para os membros do Mercosul e alguns países africanos. Com a instalação do Eresul na Sedai, o relacionamento direto com a agência diminuiu. No entanto, a ABC desenvolve até hoje projetos de cooperação diretamente com secretarias específicas, sem interlocução com a Sedai. $^{10}$

Uma das principais linhas de cooperação iniciada na SEAI e que se mantém até hoje é a que envolve os acordos de irmanação com governos subnacionais estrangeiros, sendo o com Shiga, no Japão, o que mais ações gerou. Firmado em 1980, esse acordo se mantém ativo com o intercâmbio freqüente de técnicos e o desenvolvimento de algumas pesquisas conjuntas. Entre os motivos para essa continuidade, está o fato de que a província envia anualmente missões ao estado para discutir as ações do intercâmbio, o que resulta em compromissos para os governos gaúchos, e que este é o único acordo que possui instrumentos concretos de cooperação, como rubrica orçamentária que permite o intercâmbio de técnicos. Com outros governos não centrais, os relacionamentos não possuem a mesma institucionalização. Há acordos de irmanação com Jamtland, Suécia (1993); Valparaíso, Chile (1996); Manitoba, Canadá (1997); Vêneto, Itália (2001); e Hubei, China (2001). Alguns deles geraram atividades somente nos primeiros momentos, como Jamtland, Manitoba e Valparaíso, mas os outros, mesmo sem a institucionalização alcançada no acordo com Shiga, são mais intensos.

Atualmente, as ações de cooperação internacional, no âmbito da Sedai, estão basicamente restritas à manutenção dos relacionamentos com as regiões-irmãs. Também se presta apoio a missões organizadas por outros governos subnacionais, principalmente de províncias chinesas, cujos responsáveis têm visitado com frequiência o esta- 
do. O governo demonstra querer imprimir um caráter mais comercial a esses relacionamentos, no sentido de tornar os parceiros canais de entrada para produtos gaúchos em seus países, mas, até o momento, não foram desenvolvidas estratégias com esse fim. É interessante que, na criação da Sedai, definiu-se em lei que a cooperação internacional deveria voltar-se para "formular as diretrizes do sistema de cooperação internacional em nível financeiro e empresarial" (RIO DE JANEIRO, 1995), o que não se concretizou, pois não foram definidas estratégias ou criadas políticas ou programas que possibilitassem essa mudança de rumo.

\section{A Agenda Externa de Porto Alegre}

A agenda internacional de Porto Alegre, desenvolvida ao longo de pouco mais de dez anos - desde a criação da Secar, em 1994, até a saída do PT do governo municipal a partir de 2005 -, esteve baseada em uma estratégia visível, bem articulada e que buscou a maior coerência possível com o projeto político do PT em sua dimensão internacional. Após a mudança de governo, a vontade de manter os ganhos obtidos no período anterior traduziu-se no intento de dar continuidade a essa agenda, que experimentou, mesmo assim, um inevitável processo de reconfiguração a partir das novas orientações políticas do governo de centro-direita que sucedeu ao do PT.

As principais dimensões dessa estratégia, que sintetizamos em quatro, estão mais ou menos explícitas em uma série de documentos internos elaborados pelos responsáveis pela Secar em seus primeiros anos de funcionamento. Partindo da idéia de que era preciso "ir mais além da captação de recursos", foram estabelecidas pautas de ação que regeram a ação exterior de Porto Alegre durante todo o período de permanência do PT no governo municipal. 
A dimensão mais visível dessa estratégia consistiu em potencializar a cooperação ativa com outros governos municipais, tentando desenvolver relações bilaterais sólidas e, também, fomentar a cooperação em rede, tanto no âmbito regional (Mercosul) como em nível global. Uma segunda dimensão consistiu no desenvolvimento de uma estratégia de image building para Porto Alegre, buscando difundir uma imagem internacional atrativa de uma cidade que, por suas dimensões e localização, era pouco conhecida fora das fronteiras do Brasil. A terceira dimensão da estratégia, traçada ainda antes da constituição da Secar, consistiu na busca ativa de recursos internacionais provenientes de agências multilaterais para desenvolver projetos de infra-estrutura e com fins sociais. Em quarto lugar, as atividades de promoção econômica e comercial concentraram-se no apoio às pequenas e médias empresas locais para competir no mercado internacional.

As quatro dimensões, como indicamos, figuram já nos primeiros documentos "estratégicos" elaborados na Secar durante seus primeiros anos de funcionamento, em uma etapa que podemos considerar, então, como de formação da agenda. Entre 1997 e 2000, período coincidente com a administração do prefeito Raul Pont, a agenda internacional de Porto Alegre experimentou uma etapa de consolidação, sem modificações institucionais nem introdução de novas prioridades, mas com um crescimento importante das atividades desenvolvidas. Depois, entre janeiro de 2001 e dezembro de 2004, coincidindo com a quarta e última das administrações municipais sucessivas do PT (Genro e Verle), a atividade internacional viveu um dinamismo sem precedentes. Esse dinamismo e as importantes transformações qualitativas da agenda nos permitem falar de "um salto adiante" para referirmo-nos à agenda internacional de Porto Alegre nesse período. Por último, a agenda atual, iniciada com a troca de governo em janeiro de 2005, possui traços visíveis de continuidade com respeito à gestão do governo anterior e, ao mesmo tempo, com inevitáveis redireciona- 
mentos. A seguir, consideramos a evolução de cada uma dessas quatro dimensões da agenda e os instrumentos usados em sua implementação.

\section{A cooperação política e técnica}

Quando a Secar foi criada, Porto Alegre já mantinha contatos informais com municípios de outros países de maneira ocasional e também havia institucionalizado suas relações de cooperação com alguns deles mediante a celebração de acordos de irmanação, mantendo contatos não muito sistemáticos com as cidades-irmãs. ${ }^{11}$ Ao traçarem uma estratégia internacional para o médio e o longo prazo, os responsáveis pela Secar propuseram-se a ir além das tradicionais relações de irmanação, sem as abandonar, especialmente nos casos em que funcionavam bem, como é o caso das relações com a cidade japonesa de Kanasawa, a primeira cidade a irmanar-se com Porto Alegre. A partir de então, buscou-se priorizar as relações internacionais com cidades segundo alguns critérios preestabelecidos e de acordo com os interesses estratégicos de Porto Alegre. Foram privilegiadas as relações bilaterais com as seguintes categorias de cidades: as governadas pela esquerda ou com governos de esquerda durante longos períodos de tempo; as capitais do Mercosul; as com experiências interessantes em matéria de gestão e de políticas públicas comerciais; as com um papel destacado nas redes internacionais de cidades; e as com atrativos como interlocutores comerciais potenciais.

Bolonha, Barcelona, Paris, Montevidéu, Buenos Aires e Santiago estão entre as cidades com as quais Porto Alegre estreitou relações levando em conta um ou mais desses critérios. A celebração de semanas culturais (como a Semana de Porto Alegre em Buenos Aires, a Semana de Porto Alegre em Montevidéu e a Semana de Buenos Aires em Porto Alegre) e a assinatura de acordos de cooperação, como os assinados com Barcelona (1999, 2002), Florença (2001) e Paris 
(2002), estabelecendo áreas específicas sobre as quais intercambiar experiências, foram os instrumentos institucionalizados empregados com mais freqüência. Também foram utilizados instrumentos não institucionalizados, como visitas mútuas de prefeitos e de outros quadros municipais.

Além de potencializar as relações bilaterais com cidades consideradas de interesse estratégico, o governo de Porto Alegre envolveu-se paulatinamente em ações de cooperação em rede com outros municípios, inicialmente no espaço Mercosul e, em seguida, participando e criando - redes de cooperação em âmbito global.

No Mercosul, Porto Alegre esteve entre os principais instigadores da criação de uma rede de municípios para promover os interesses dos governos locais e estimular atividades de cooperação intermunicipal, objetivo que se concretizou com o estabelecimento, em fins de 1995, da Rede Mercocidades, que seguia os fundamentos da Eurocidades, rede de municípios europeus. Porto Alegre e, mais especificamente, o prefeito Genro e o secretário Utzig, tiveram um papel importante na tarefa de promover a iniciativa e persuadir outras prefeituras da região para que se unissem à Mercocidades. Por esse motivo, Porto Alegre acolheu a reunião preparatória da Mercocidades e ocupou a Secretaria Executiva Provisória durante 1995. Nesse ano, a Prefeitura estabeleceu contatos intensos e sistemáticos com outras cidades para garantir ampla participação no encontro em Assunção, onde se estabeleceu formalmente a rede, e para elaborar a carta de princípios e o estatuto da rede, aprovados nessa mesma reunião. Foi também a Prefeitura de Porto Alegre a encarregada de legitimar a rede Mercocidades perante o próprio governo brasileiro e o Itamaraty. Após esse início, foi Assunção que ocupou a secretaria executiva, para, no ano seguinte, devolver o cargo a Porto Alegre, sede também da secretaria executiva do Mercosul em 1997. Porto Alegre também se empenhou ativamente na criação da Reunião Especializada de Municípios e Intendências (REMI), que ocorreu em dezembro de 
2000 e foi um passo importante na institucionalização de uma instância especificamente voltada ao tratamento dos temas de interesse para as cidades no Mercosul.

A participação ativa de Porto Alegre na criação de estruturas de cooperação intermunicipais em âmbito global é posterior e é um dos elementos do "salto adiante" na agenda internacional que se iniciou com a segunda administração de Tarso Genro, em 2001. Essa participação se manifestou, em primeiro lugar, no papel ativo que Porto Alegre exerceu, junto com São Paulo (também governada nesse período pelo PT), nas negociações políticas no seio das duas grandes associações mundiais de cidades (União Internacional de Autoridades Locais (em inglês, International Union of Local Authorities IULA) e Federação Mundial de Cidades Unidas (FMCU)) com vistas a sua unificação e a criação de uma única organização universal que representasse os interesses dos governos locais dentro e fora do sistema das Nações Unidas. Essa unificação ocorreu em 2004, com o estabelecimento da Cidades e Governos Locais Unidos (CGLU). Mesmo que Porto Alegre fosse membro da IULA (a organização de cidades "de esquerda") desde 1997, foi somente na segunda administração Genro que a "política internacional das cidades" começou a ser considerada seriamente pelas autoridades municipais de Porto Alegre, desde então com grande ativismo.

Em segundo lugar, Porto Alegre realizou uma contribuição própria ao tecido institucional do internacionalismo municipalista, projetando e promovendo o primeiro Fórum de Autoridades Locais pela Inclusão Social (FAL), evento celebrado anualmente a partir de 2001. Logo foi criada também uma rede de cooperação, a Rede FAL, unindo os principais protagonistas do Fórum. O FAL, também conhecido como Fórum de Autoridades Locais pela Inclusão Social de Porto Alegre, é um evento que se celebra anualmente em conexão com o Fórum Social Mundial (geralmente ocorre alguns dias antes, na mesma cidade) e compartilha, essencialmente, suas mesmas orientações e objetivos. No FAL, os representantes de municípios de 
todo o mundo (uns quinhentos nos eventos de maior participação) discutem problemáticas globais vinculadas à luta contra a exclusão social, tais como pobreza, violação de direitos humanos e injustiças sociais, e compartilham informações, incluindo boas práticas. A constituição da Rede FAL, decidida em 2002, mas que somente se efetivou em 2005, supõe um passo a mais na luta organizada dos municípios contra a exclusão social. A rede tem vínculos estreitos com o Fórum Social Mundial, sendo membro de seu Conselho Internacional, e, também, com a CGLU, dentro da qual integra a Comissão de Inclusão Social (CIS). Porto Alegre, de onde partiu a iniciativa de criar o FAL, acolheu quatro das seis edições realizadas até agora e teve também um papel fundamental na criação da rede ${ }^{12}$ e na elaboração do que até o momento é o produto mais relevante: a Agenda 21 das Cidades para a Cultura. ${ }^{13}$ Em terceiro lugar, merece destaque o papel de Porto Alegre no programa de cooperação intermunicipal descentralizada Urb-Al, do qual participaram municípios latino-americanos e europeus sob os auspícios da União Européia, que financiou parcialmente as ações. Em 2002, Porto Alegre obteve a coordenação de uma das treze redes temáticas do programa, a Rede 9 , sobre financiamento local e orçamento participativo, além de participar em outras duas, ${ }^{14}$ no seio da qual se desenvolveram mais de uma dezena de projetos até o encerramento do programa em 2006. É de se destacar que Porto Alegre continuou coordenando a rede mesmo com a saída do PT do governo.

\section{A estratégia de construção de uma imagem internacional}

Em 1994 e 1995, quando se estabeleceu o Gabinete Extraordinário e, em seguida, a Secar, a cidade de Porto Alegre era muito pouco conhecida além das fronteiras brasileiras. Atualmente, ela é bem conhecida no mundo, principalmente por duas razões: por ter acolhido o Fórum Social Mundial - o evento antiglobalização que faz contraponto ao 
Fórum Econômico de Davos -, em quatro das seis edições celebradas até agora, e por ser a origem e o principal centro difusor da prática de distribuição de recursos públicos conhecida como Orçamento Participativo (OP). Tal como explicaremos a seguir, a imagem de Porto Alegre no mundo, consideravelmente difundida e centrada nas características de "cidade global solidária", é resultado, em grande medida, de uma bem pensada decisão de difundir essa imagem e, também, parte da estratégia de internacionalização desenvolvida pelos responsáveis pela Secar.

A decisão de criar uma "marca Porto Alegre" foi um elemento presente desde o princípio na estratégia de internacionalização da cidade. Entre outras coisas, os responsáveis municipais encarregados de elaborar uma estratégia internacional para Porto Alegre consideraram que as negociações com agências internacionais para a obtenção de recursos seriam facilitadas se seus interlocutores pudessem situar a cidade no mapa e associá-la a uma imagem positiva. Ademais, já se contava, na época, com diversos exemplos de cidades que haviam desenvolvido, com êxito, estratégias de internacionalização nas quais a construção de uma imagem havia sido um aspecto fundamental. Os responsáveis pela Secar consideraram profundamente o exemplo de Barcelona, uma cidade com uma imagem internacional que explora seu próprio modelo de cidade e suas práticas de gestão urbana. De maneira similar, tratava-se de construir a imagem internacional de Porto Alegre a partir de um traço que fosse ao mesmo tempo próprio e exportável - e o OP reunia esses dois requisitos. Implantado originalmente em Porto Alegre sob o impulso do PT, era um bom trampolim para apresentar a cidade ao mundo como "capital da democracia participativa". Ademais, o OP já começara a ser implantado com relativo êxito em outras cidades dentro e fora do Brasil.

A celebração da Cúpula das Cidades (ou Conferência Hábitat II), em junho de 1996, foi uma excelente oportunidade para divulgar a prática do OP internacionalmente. O prefeito Genro e o secretário Utzig participaram da cúpula e das atividades paralelas, divulgando o OP. 
Além disso, a decisão de revitalizar o programa ONU-Hábitat, tomada na conferência, abriu novas possibilidades de cooperação intermunicipal. São realizados, desde então, um programa de melhores práticas e um concurso, financiado por Dubai, que, desde 1996, premia as contribuições de destaque para melhorar a qualidade de vida e a sustentabilidade de cidades e comunidades, agrupando, além disso, todas as demais práticas finalistas - classificadas como "melhores" ou "boas" - em um banco de dados para promover a sua difusão. O OP de Porto Alegre foi uma das quarenta práticas classificadas como "melhores" na edição de 1996 do concurso, renovando-se esse reconhecimento na convocatória de 2000.

Assim, em pouco tempo, o OP converteu-se não somente na principal senha de identidade de Porto Alegre, como também no ativo mais importante que a cidade oferecia em matéria de cooperação. Um indicador de que era um ativo bem valorizado por potenciais interlocutores é que tanto as viagens do prefeito como as visitas de delegações estrangeiras a Porto Alegre foram centrando-se, cada vez mais, respectivamente, na difusão dessa prática e na vontade de se familiarizar com ela.

Levando-se isso tudo em conta, é evidente que a decisão do comitê organizador do Fórum Social Mundial de celebrá-lo em Porto Alegre estava relacionada com a imagem de cidade solidária que fora provocada internacionalmente a partir da difusão do OP, ainda que isso não exclua outras razões. O perfil de Porto Alegre como cidade solidária e capital internacional da democracia participativa, com efeito, casava bem com as características do Fórum.

As autoridades municipais souberam aproveitar bem a oportunidade que lhes oferecia a celebração de um evento como o Fórum e não se limitaram a ser receptoras passivas do mesmo - contribuíram ativamente para a sua organização, sobretudo a partir da segunda edição. A organização do Fórum converteu-se em um tema prioritário da agenda exterior municipal e, dado seu caráter "político", decidiu-se, 
como já vimos, transferir a equipe do setor de cooperação internacional da Secar para o próprio gabinete do prefeito, pois se considerava necessária (e rentável) uma supervisão direta da instância política superior.

Na última das administrações do PT, Porto Alegre viveu seu ponto culminante de atividade e reconhecimento internacional a partir da exploração de uma imagem de cidade global solidária baseada na difusão exterior de uma prática interna de governança, o OP, e da acolhida e co-organização de um evento mundial cujo perfil político estava bem sintonizado com o discurso internacional do PT.

Levando isso em conta, é de se destacar a opção do governo que substituiu o PT de manter, na medida do possível, não somente essa imagem da cidade, como também a mesma lógica de construção de uma imagem internacional. A promoção de Porto Alegre como "cidade rede da democracia" por parte do governo entrante partiu do reconhecimento dos sucessos alcançados na administração anterior. Além disso, de maneira similar à difusão do OP fora do Brasil empreendida pelo PT, o atual governo aproveita todas as oportunidades para difundir a "governança local solidária", um programa municipal de parcerias para o desenvolvimento entre diferentes atores locais.

\section{A captação de recursos internacionais}

A busca de recursos internacionais costuma ser a motivação principal da ação exterior municipal em todo o mundo. Em Porto Alegre, como vimos, o embrião da estrutura paradiplomática foi, precisamente, o Gabinete Extraordinário para a Captação de Recursos, voltado à busca de fundos tanto nacionais quanto internacionais. A Secar constituiu-se com base em dois pilares, um dos quais era a coordenação da captação de recursos. No entanto, seguindo a mesma linha traçada quando se constituiu o Gabinete, os recursos que se tentava captar eram exclusivamente recursos públicos provenientes de agências internacionais. 
Diferentemente da maioria dos municípios com estruturas de captação de recursos, enquanto esteve governada pelo PT, a Prefeitura de Porto Alegre não buscou ativamente investimentos privados. Em parte, era assim porque os tipos de projetos - de infra-estrutura ou de caráter social - nos quais investiam os auxílios não eram rentáveis para os investimentos privados, mas tampouco houve um interesse especial em colocar em marcha esse tipo de política.

O trabalho do setor de captação de recursos consistia, basicamente, na identificação de fontes potenciais de financiamento e na elaboração e apresentação de projetos aos organismos financiadores. Iniciando com a abertura das negociações com o BID para a construção da Terceira Perimetral (uma rota de circulação rápida que circunda a cidade), em 1995, a área de captação de recursos alcançou um nível muito satisfatório na preparação de projetos e bom conhecimento sobre as potenciais fontes de financiamento internacional. Logo esses conhecimentos e experiências começaram a ser compartilhados com outras prefeituras do Rio Grande do Sul e de outros estados brasileiros por meio da organização freqüente de reuniões, seminários e outras atividades, até a saída do PT do governo municipal.

A captação de recursos foi a dimensão da agenda que mais mudou com o novo governo. Diferentemente do PT, a ênfase recaiu sobre a atração de investimentos privados, sendo a cooperação público-privada o principal eixo de intervenção. A isso se dedica a Captare, o novo nome - com conotações, por certo, muito claras com o qual se rebatizou a Secar.

\section{A promoção econômico-comercial direta}

Em uma ou outra medida, a obtenção de benefícios econômicos para Porto Alegre estava implícita em todas as dimensões da estratégia internacional desenvolvida pela Secar. Mas a dimensão mais diretamente orientada para isso foi a realização de atividades de promoção 
das exportações, voltada ao apoio das pequenas e médias empresas do município em suas tentativas de competir no mercado internacional. O principal instrumento de promoção das exportações consistiu na instalação, conjuntamente com o governo do Estado, do Trade Point, já descrito anteriormente. O uso de outro instrumento de promoção comercial típico, a organização de missões comerciais ao exterior, previsto nos documentos estratégicos da Secar, foi pouco empregado, em parte porque a relação entre a Prefeitura e o empresariado (e as câmaras de comércio) não foi muito fluida durante as administrações petistas e também porque os empresários porto-alegrenses podiam participar de missões organizadas pelos governos estadual e federal. Por último, cabe mencionar a elaboração, por parte da Secar, de distintos materiais impressos que apresentavam Porto Alegre como "uma cidade com a qual se pode comerciar".

Com a mudança de governo, a relação da Prefeitura com os representantes do empresariado mudou radicalmente, e as duas pessoas que dirigiram a Captare até o momento ocuparam cargos importantes na representação de interesses empresariais. Além disso, abandonou-se a política anterior de privilegiar a promoção da pequena e da média empresa.

\section{As Agendas Externas do Río Grande do Sul e do Porto Alegre. Elementos de Comparação}

Tal como fizemos com respeito às estruturas paradiplomáticas no apartado final da seção anterior, procuramos aqui comparar as respectivas agendas externas do Rio Grande do Sul e de Porto Alegre, tentando determinar em que medida elas são características de um ou de outro tipo de atores mistos. 
Em primeiro lugar, ao considerar globalmente as agendas, salta à vista a diferença quanto ao grau de articulação de uma e de outra. Enquanto a agenda internacional de Porto Alegre correspondeu a uma estratégia explícita e que, na prática, conseguiu desenvolver-se conforme o previsto, a agenda internacional do Rio Grande do Sul aparece muito menos estruturada e com um grau de correspondência bem menor entre os objetivos propostos e os resultados alcançados. Parece evidente que isso não esteja relacionado com o fato de serem atores diferentes, mas sim por Porto Alegre ter sido governada pelo mesmo partido durante quatro administrações sucessivas, o que the permitiu elaborar e manter uma agenda internacional mais coesa e coerente e menos sujeita à mudança que a do governo estadual, o qual não teve, desde 1987, a mesma força no poder em gestões consecutivas. Também não consideramos que a bem-sucedida estratégia de construção de imagem empreendida por Porto Alegre tenha a ver com sua condição de governo local. Por um lado, porque existem numerosos exemplos de estratégias semelhantes desenvolvidas por governos regionais e, por outro, pois sua implementação depende de recursos controlados pelos próprios atores (governos locais ou regionais) e, como no caso do orçamento participativo, de Porto Alegre, da valorização das atuações e políticas públicas empreendidas e desenvolvidas autonomamente por eles. Os governos subnacionais (locais e regionais), portanto, são totalmente livres para empreender esse tipo de atuação se o considerarem conveniente.

Em segundo lugar, ao dirigir nossa atenção para as temáticas presentes em ambas as agendas, encontramo-nos com o fato de que os dois atores considerados enfatizaram de modo distinto as duas grandes dimensões que conformam qualquer agenda internacional de um governo não central: a da promoção econômica e a da cooperação técnico-política. No caso do Rio Grande do Sul, a cooperação sempre foi uma dimensão menor da atuação externa e, em determinados momentos, tentou-se até mesmo subordiná-la aos objetivos de promo- 
ção econômica. A promoção de exportações e a atração de investimentos constituíram, de longe, os principais objetivos da ação externa do Rio Grande do Sul, que também abordou o processo de integração regional do Mercosul a partir de uma perspectiva eminentemente econômica. Porto Alegre, no entanto, focalizou sua ação externa na cooperação técnica e política. As atuações dirigidas à promoção comercial foram modestas e a atração de investimentos concentrou-se na captação de recursos de agências públicas para o desenvolvimento de infra-estrutura pública. No Mercosul, tentou-se potencializar o desenvolvimento institucional e uma maior participação dos governos subnacionais no processo de integração. Em nosso entender, esses focos diferentes nas distintas dimensões da agenda têm a ver com as naturezas diferentes dos dois tipos de atores que consideramos.

Os governos regionais - em maior medida que os locais - são os defensores naturais dos interesses econômico-comerciais do território que governam, sobretudo em casos em que, como no Brasil, o marco legislativo leva a uma concorrência intensa entre os estados pelos investimentos estrangeiros. Nesse sentido, o foco econômico-comercial da agenda do Rio Grande do Sul é típico de um ator regional, com mais responsabilidade que um ator local, embora não necessariamente com mais competências. Igualmente, a ênfase que Porto Alegre dá à cooperação intermunicipal, típica dos governos locais, obedece, em boa medida, a uma espécie de divisão de funções entre o governo regional e o local, ainda que também intervenham aqui outros fatores de natureza político-ideológica.

Em terceiro e último lugar, também encontramos uma forte relação entre os instrumentos empregados pelos dois atores para atingir seus objetivos externos e sua condição de governo regional e local. Como é obvio, o tipo de instrumento empregado está em grande parte condicionado pela agenda. Assim, no caso do Rio Grande do Sul, destaca-se o uso extenso que se fez de instrumentos clássicos de promoção comercial, como o envio de missões comerciais ao exterior (com pre- 
sença do governo regional e empresários) e participação em feiras. Porto Alegre, por sua vez, confeccionou um amplo catálogo de instrumentos de cooperação centrado no intercâmbio de boas práticas. Não obstante, também deve ser destacada (pois não está tão ligada à agenda) a preferência de Porto Alegre pelos instrumentos multilaterais e pela cooperação em rede, que contrasta com a tendência do Rio Grande do Sul em privilegiar as relações bilaterais com outras regiões. Mais uma vez, os dois atores estudados têm comportamentos típicos do seu gênero. A cooperação multilateral e o trabalho em rede entre governos locais costumam funcionar melhor que as iniciativas desse tipo empreendidas por governos regionais. Isto é assim, sobretudo, porque os governos regionais são muito mais heterogêneos que os locais (em financiamento, competências e presença ou não de objetivos nacionalistas) e lhes custa mais que aos governos locais encontrar interesses comuns com regiões de outros países. Ademais, o fato de que a agenda econômica das regiões é, muitas vezes, similar à do Estado central faz com que muitos temas possíveis de cooperação inter-regional sejam abordados diretamente por meio de regimes internacionais.

\section{Conclusão}

Neste artigo, analisamos comparativamente a ação exterior do governo estadual do Rio Grande do Sul e a da Prefeitura de Porto Alegre, centrando nossa atenção na evolução das respectivas estruturas paradiplomáticas e agendas.

Nosso principal objetivo, tal como dissemos na Introdução, era contribuir, a partir da análise de dois casos concretos, para a conceituação de dois tipos de governos subnacionais como atores internacionais: os regionais (ou de nível intermediário) e os locais.

O ponto de partida dessa análise foi a idéia, bastante difundida na literatura sobre a matéria, de que tanto os governos regionais como os 
locais podem ser considerados atores internacionais mistos, em parte condicionados pela soberania que compartilham com outros governos no território que administram, mas também mais livres que os governos centrais no que diz respeito a suas opções de política exterior, com algumas pautas de atuação semelhantes às dos atores não estatais. Por meio da análise comparativa dos dois casos, pretendíamos estabelecer diferenças entre a maneira como os governos regionais e os locais combinam as características dos atores livres de soberania e as dos atores condicionados pela soberania.

Embora a análise de nossos casos não nos permita chegar a conclusões indiscutíveis, possibilita-nos formular a hipótese de que existem diferenças significativas nesse sentido. As limitações e responsabilidades próprias dos atores internacionais condicionados pela soberania teriam maior peso nos governos regionais que nos locais, $\mathrm{e}$ estes, por sua vez, gozariam em maior grau das liberdades e possibilidades dos atores internacionais livres de soberania.

Tanto em estruturas e procedimentos como em substância, a ação exterior do governo do Rio Grande do Sul parece inspirada, principalmente, na do governo central. A estrutura institucional do seu aparato paradiplomático - desenvolvida inicialmente segundo o modelo do MRE-, a complexidade da agenda e a primazia dos interesses econômicos sobre os sociais como principais propulsores das políticas assim parecem demonstrá-lo. O mesmo pode dizer-se da tentativa não concluída - de abrir escritórios de representação no exterior, um instrumento usado por vários governos regionais em todo o mundo. Além disso, embora os mecanismos de articulação com a política exterior do governo central sejam bastante pobres (e, mais do que mecanismos que buscam uma contribuição do governo regional à formulação da política exterior do Estado, parecem, na verdade, formas de supervisão da ação exterior do governo regional pelo governo central), no futuro poderiam possibilitar uma contribuição efetiva dos governos regionais à política exterior brasileira. Por outro lado, dife- 
rentes atuações, como as iniciativas de cooperação transfronteiriça, representam a outra dimensão de ator misto do Rio Grande do Sul, mais próxima dos atores livres de soberania.

Na ação exterior de Porto Alegre, no entanto, dá-se uma combinação diferente das duas dimensões. Sua agenda muito mais focalizada (em temas sociais) e a intensa participação nas redes transnacionais de autoridades locais parecem mais próprias dos atores livres de soberania que dos condicionados pela soberania. Por outro lado, a procura de instrumentos de desenvolvimento da coletividade cidadã em geral como principal motivação da ação exterior municipal - evidente na estratégia internacional de Porto Alegre - representa a dimensão de atuação mais condicionada pela soberania (no sentido de responsabilidade pelo bem-estar e pelo desenvolvimento cidadão) desta segunda categoria de ator misto.

São necessários, naturalmente, mais estudos de caso comparando a ação exterior de governos regionais e locais para, em primeiro lugar, verificar a validade de nossa caracterização e, em segundo, aprimorá-la. Os já numerosos estados e municípios brasileiros com atividade exterior regular e institucionalizada são, no nosso modo de ver, objetos de estudo perfeitamente apropriados para essa tarefa.

\section{Notas}

1. A Assessoria de Relações Internacionais do governo do Rio de Janeiro foi criada em 1983.

2. Na área de Cooperação, havia as divisões de Cooperação Técnica Internacional, Cooperação Técnica entre Países em Desenvolvimento e Cooperação com Estados-irmãos. Para os Negócios Internacionais, as divisões eram de Eventos Internacionais e de Cooperação Empresarial e Promoção de Negócios. Na área da Integração Regional, eram de Documentação e Informação, de Assuntos Fronteiriços, de Integração Cultural e de Estudos Latino-americanos. 
3. Exceções foram o internacionalista Ricardo Seitenfus, o primeiro secretário da SEAI e responsável pelo projeto que a criou, e Luiz Carlos Tomazelli, administrador de empresas e o primeiro secretário na gestão de Alceu Collares.

4. Integração Latino-americana, Cooperação Internacional, Negócios Internacionais, Redes de Negócios Internacionais e Relações Consulares.

5. A primeira, de caráter mais "econômico", agrupava os setores de Comércio Exterior, Redes de Negócios e Feiras Internacionais; na outra, mais "política", estavam os setores de Relações Consulares, Cooperação Internacional, Mercosul e Movimentos Sociais Internacionais - este último uma novidade, que tinha por objetivo promover o relacionamento do governo com entidades não governamentais.

6. Na primeira, permanecem os setores de Cooperação Internacional e de Relações Consulares, sendo extinto o de Movimentos Sociais Internacionais, criado o de Missões Governamentais Internacionais, e renomeado como Assuntos da América Latina o que trata de temas da integração regional. Na segunda, foi mantido o setor de Feiras Internacionais e criada a Sala do Exportador, um serviço de atendimento direto aos exportadores.

7. No governo de Luiz Inácio Lula da Silva, ocorreram alguns eventos em Brasília para discutir assuntos de interesse dos governos subnacionais, como a reunião sobre Cooperação Internacional Federativa: Instrumentos e Desafios (12/2/2004), o I Seminário sobre Coordenação Federativa para a Promoção de Exportações (9/11/2004) e o Encontro sobre Negociações Internacionais (8/8/2006). Ressalte-se que essas iniciativas buscam mais expor as ações do governo federal a esses níveis de governo do que propriamente estimular uma concertação de interesses.

8. Estimulou-se a aproximação entre a Crecenea Litoral constituída pelas províncias de Corrientes, Chaco, Entre Rios, Formosa, Misiones e Santa Fé, e o Codesul, formado à época por Rio Grande do Sul, Santa Catarina e Paraná e, mais tarde, por Mato Grosso do Sul.

9. Os GITs eram os de Aspectos Fronteiriços (subgrupos Defesa Civil e Agricultura), Saúde, Educação, Cultura, Turismo, Meio Ambiente, Segurança, Infra-Estrutura (subgrupos Transporte, Comunicação e Gasoduto), Ciência e Tecnologia, Cooperação Técnica e Conselhos Profissionais.

10. Exemplos são os programas realizados pela Secretaria da Saúde, como o Primeira Infância Melhor, e pela Secretaria da Educação, como o Escola Aberta, apoiados pela Organização das Nações Unidas para a Educação, a Ciência e a Cultura (em inglês, United Nations Educational, Scientific and Cultural Organization - UNESCO) e negociados com a ABC sem conhecimento da Sedai. 
A Ação Externa dos Governos Subnacionais no Brasil: Os Casos do Rio Grande do Sul...

11. As cidades-irmãs de Porto Alegre são Kanazawa, Japão (1967); Morano Calabria, Itália (1982); Ribeira Grande, Portugal (1982); La Plata, Argentina (1982); Punta del Este, Uruguai (1984); Natal, Brasil (1992); Horta, Portugal (1993); Rosário, Argentina (1994); São Petersburgo, Rússia (2000); Portalegre, Portugal (2000); Austin, EUA (2002); Suzhou, China (2004).

12. A secretária executiva da Rede FAL é uma ex-funcionária da prefeitura de Porto Alegre.

13. A Agenda 21 das Cidades para a Cultura é um documento elaborado a partir do exemplo da Agenda 21 para o Meio Ambiente. Foi aprovada em 2004, por cerca de mil representantes de governos locais, a iniciativa de Porto Alegre e Barcelona e contém o compromisso dos governos locais de fazer da cultura uma dimensão-chave das suas políticas urbanas.

14. A Rede 10, "luta contra a pobreza urbana", coordenada por São Paulo, e a Rede 13, "cidade e sociedade da informação", coordenada por Bremen.

\section{Referências Bibliográficas}

BARRETO, Maria Inês. Gestão estratégica do poder Executivo do estado de São Paulo frente ao processo de integração regional do Mercosul. 2001. Tese (Doutorado em Administração de Empresas) - Escola de Administração de Empresas de São Paulo, Fundação Getulio Vargas, São Paulo, 2001.

BOGÉA, Antenor. A diplomacia federativa: do papel internacional e das atividades externas das unidades federativas nos Estados Nacionais. Tese (Trabalho final em Diplomacia, XLII Curso de Altos Estudos) - Instituto Rio Branco, Brasília, 2001.

DUCHACEK, Ivo. Perforated sovereignties: towards a tipology of new actors in International Relations. In: MICHELMANN, H. J.; SOLDATOS, P. Federalism and International Relations. The role of subnational units. Oxford: Clarendon Press, 1990.

FARIAS, Débora. Federalismo e Relações Internacionais. Dissertação (Mestrado em Relações Internacionais ) - Universidade de Brasília, Brasília, 2000. 
HOCKING, Brian. Regionalismo: uma perspectiva das Relações Internacionais. In: VIGEVANI, Tullo et al. (Org.). A dimensão subnacional e as Relações Internacionais. São Paulo: Educ/Unesp/EdUSC, 1997-2004. p. 77-107.

KEOHANE, Robert O.; NYE, Joseph. Power and interdependence: world politics in transition. Boston: Little Brown \& Co, 1997.

KINCAID, John. Constituent diplomacy in federal parties at the Nation State: conflict and political cooperation. In: MICHELMAN, H. J.; SOLDATOS, P. (Ed.). Federalism and International Relations: the role of subnational units. Oxford: Clarendon Press, 1990.

Constituent diplomacy: U.S. state roles in foreign affairs. In: ELAZAR, Daniel (Ed.). Constitutional design and power sharing in the post-modern epoch. Lanham: Jerusalem Center for Public Affairs and University Press of America, 1991. p. 107-142.

LAMPREIA, Luiz Felipe. Diplomacia brasileira: palavras, contextos e razões. Rio de Janeiro: Lacerda Editores, 1999.

LESSA, J. V. da S. A paradiplomacia e os aspectos legais dos compromissos internacionais celebrados por governos não centrais. Tese (Trabalho final em Diplomacia, XLIV Curso de Altos Estudos) - Instituto Rio Branco, Brasília, 2002.

MACADAR, Beky. A influência do Mercosul na atração de investimentos diretos estrangeiros e na ampliação da infra-estrutura do RS. Indicadores Econômicos FEE, v. 26, n. 4, p. 113-128, 1999.

MATTOSO, Jorge. Relações internacionais e poder local: o caso de São Paulo. Política Externa, v. 10, n. 3, p. 113-121, dez. 2001.

MERLE, Marcel. Sociologie des relations internationales. Paris: Dalloz, 1988.

NUNES, Carmen J. da S. A paradiplomacia no Brasil: o caso do Rio Grande do Sul. Dissertação (Mestrado em Relações Internacionais) - Universidade Federal do Rio Grande do Sul, Porto Alegre, 2005a.

O Rio Grande do Sul no contexto da integração regional do Mercosul. In: HOFMEISTER, Wilhelm (Org.). Anuário Brasil-Europa 2005. Rio de Janeiro: Konrad-Adenauer-Stiftung, 2005b. p. 117-141. 
A Ação Externa dos Governos Subnacionais no Brasil: Os Casos do Rio Grande do Sul...

PAQUIN, Stéphane. Paradiplomatie e relations internationales. Bruxelles: Peter Lang, 2004.

Québec e a crise política canadense. Tempo Exterior, v. VI, n. 10, p. 5-12, 2005.

PASTOR, Manuel; WISE, Carol. The origins and sustainability of Mexico's free trade policy. International Organization, v. 48, n. 3, p. 459-489, 1994.

RIO DE JANEIRO (Estado). Artigo 5², Decreto nº 35.915, de 12 de abril de 1995. Dispõe sobre a estrutura básica da Secretaria do Desenvolvimento e de Assuntos Internacionais. Rio de Janeiro.

RISSE, Thomas. Transnational actors in world politics. In: CARLSNAES, W.; RISSE, T. B. Simmons (Ed.). Handbook of International Relations. London: Sage, 2002. p. 255-274.

ROSENAU, James. Turbulence in world politics. Princeton: Princeton University Press, 1990.

SALOMÓN, Mónica. Os novos actores globais no sistema de Nacións Unidas. Tempo Exterior, v. VI, n. 10, p. 81-93, 2005.

; SÁNCHEZ CANO, Javier. El proceso de articulación de las autoridades locales como actor político y el sistema de Naciones Unidas. Agenda ONU, Anuario de la Asociación para las Naciones Unidas en España, n. 6, p. 151-192, 2005.

SCP. Mensagem à Assembléia Legislativa - governador Antônio Britto. Porto Alegre: Secretaria da Coordenação e Planejamento, 1996.

SEITENFUS, Ricardo. Para uma nova política externa brasileira. Porto Alegre: Livraria do Advogado, 1994.

SOLDATOS, Panayotis. An explanatory framework for the study of federated states as foreign-policy actors. In: MICHELMAN, H.; SOLDATOS, P. Federalism and International Relations: the role of subnational units. Oxford: Clarendon Press, 1990. p. 34-53.

Cascading subnational paradiplomacy in an interdependent and transnational world. In: BROWN, Douglas; FRY, Earl (Ed.). States and provinces in the international economy. California: Institute of Governmental Studies Press, University of California, 1993. p. 45-64. 
VIGEVANI, T. et al. A dimensão subnacional e as Relações Internacionais. São Paulo: Educ/Unesp/EdUSC/FAPESP, 2004.

\section{Resumo}

\section{A Ação Externa dos Governos Subnacionais no Brasil: Os Casos do Rio Grande do Sul e de Porto Alegre. Um Estudo Comparativo de Dois Tipos de Atores Mistos}

No artigo são descritas e comparadas as atividades externas de dois atores subnacionais de níveis de governo diferentes: a prefeitura de Porto Alegre (nível local) e o governo estadual do Rio Grande do Sul (nível regional). Os dois atores considerados têm desenvolvido uma atividade externa destacável e pioneira no contexto brasileiro. O núcleo do artigo é a descrição e a comparação das dimensões institucional (estrutura paradiplomática) e substancial (agenda e instrumentos) dos dois governos subnacionais. Nosso principal objetivo é contribuir, a partir da análise desses casos concretos, para a conceituação diferenciada dos governos locais e dos regionais como atores internacionais. Tanto uns como outros podem ser considerados atores internacionais mistos, em parte condicionados pela soberania que compartilham com os outros níveis de governo no território que administram, mas também mais livres que os governos centrais no que diz respeito a suas opções de política exterior, com alguns pontos de atuação semelhantes às dos atores não estatais. Nossas perguntas de partida são como os dois tipos de atores conjugam as características próprias dos atores condicionados pela soberania e as dos livres e se há diferenças significativas entre a ação encaminhada nesse sentido pelos governos locais e pelos regionais.

Palavras-chave: Governos Subnacionais - Paradiplomacia - Ação Exterior - Atores Internacionais 


\section{Abstract}

\section{The Foreign Actions of Brazilian Governments: The Cases of Rio Grande do Sul and Porto Alegre. A Comparative Study of Two Kinds of Mixed Actors}

In this article we compare the external activities carried out by two subnational actors of different governmental levels: the Municipality of Porto Alegre (local government) and the State of Rio Grande do Sul (regional government). These two actors have developed external activities that are both relevant and pioneering in the Brazilian context. A description and a comparison of the institutional dimension (paradiplomatic structure) and the substantial dimension (agenda and instruments) of these two subnational governments form the core of this article. Based on the analysis of these two cases, our aim is to contribute to a more specific conceptualization of local and regional governments as international actors. Both can be considered as mixed actors, in part bound to the sovereignty they share with other levels of government over the territory they govern, in part freer than central governments as concerns their foreign policy options, sometimes acting in similar ways to non-state actors. Our initial questions refer to how these two actors conjugate characteristics of sovereignty-bound and sovereignty-free actors and whether there are relevant differences between the external activities they carry out.

Keywords: Subnational Governments - Paradiplomacy - External Action - International Actors 